\title{
Sobre las herramientas pragmalingüísticas del análisis del discurso público
}

\author{
Joanna WILK-RACIĘSKA \\ Universidad de Silesia (Polonia) \\ joanna.wilk-racieska@us.edu.pl
}

Recibido: 18 de septiembre de 2013

Aceptado: 17 de febrero de 2014

\begin{abstract}
Resumen:
El objetivo de este texto será presentar unas herramientas pragmalingüísticas que permiten descubrir y evaluar el verdadero comunicado que transmite el discurso público (mediático, político, etc.) y no la intención de su emisor. Proponemos un breve análisis de la manipulación de reglas pragmalingüísticas y de algunas infracciones -intencionadas o no- de las reglas de cohesión textual básicas que aparecen en los discursos presentados en la prensa y la televisión. En primer lugar nos centraremos en las definiciones y la metodología (una aproximación pragmalingüística a la teoría de la argumentación y el análisis del discurso) que nos serán útiles en este trabajo y, por fin, nos serviremos de ellas en la parte analítica. Palabras clave: discurso público, argumentación, persuasión, lenguaje político, comunicación.
\end{abstract}

\section{On the pragma-linguistic tools of discourse analysis}

\begin{abstract}
The goal of this paper is to present a pragma-linguístic tools for analyzing and evaluating the true message that the public discourse (media, political, etc.) transmits, and not the speaker's intention. We propose a brief analysis of the manipulation of pragma-linguístic rules and some infractions -intentional or not- of the basic textual cohesion rules that appear in the speeches made in the press and television. First we will focus on the definitions and methodology (the pragma-linguistic approach to the theory of argumentation and discourse analysis) that will be useful in this work and, finally, we will use them in the analytical part.
\end{abstract}

Keywords: Political discourse, argumentation, persuasion, political language, communication.

\section{Referencia normalizada}

WILK-RACIĘSKA, Joanna (2014): "Sobre las herramientas pragmalingüísticas del análisis del discurso público". Estudios sobre el Mensaje Periodístico. Vol. 20, Núm. 2 (julio-diciembre), págs.: 1249-1265. Madrid, Servicio de Publicaciones de la Universidad Complutense.

Sumario: 1. Introducción. 2. Definiciones y análisis básicos. 3. Análisis pragmalingüístico de la argumentación: manipulación. 4. Los principios de la cohesión de la microestructura. 5. Conclusión. 6. Referencias bibliográficas

\section{Introducción}

Se supone que todas las personas públicas han de cuidar su aspecto y tener cuidado con lo que dicen, pero, como sabemos, no siempre es así. Es bien sabido que por más refinadas e intelectuales que sean las imágenes de algunos políticos trazadas en la prensa y televisión durante las campañas electorales, los mismos políticos pueden desbaratarlas... simplemente abriendo la boca. No obstante, a lo largo de este texto no nos interesarán ejemplos explícitos de la ignorancia de los políticos y otros famosos de hoy día, puesto que esta medalla tiene también otra cara: los discursos "desbaratados" pueden también ser intencionados y servir para manipular a los interlocutores. Aplicando 
algunas de las herramientas pragmalingüísticas ${ }^{1}$ básicas a un corpus ilustrativo de los discursos pronunciados por los políticos, intentaremos descifrar el mismo lenguaje político y sus reglas, puesto que, como sostiene George Orwell (Orwell, 1946: web), "el lenguaje político está diseñado para hacer que las mentiras suenen verdaderas y el asesinato respetable, y para dar una apariencia de consistencia al puro viento"2.

La conclusión de Orwell no es nada extraña, porque aunque el análisis del lenguaje político, un lenguaje de persuasión y manipulación, es una disciplina lingüística muy bien desarrollada ${ }^{3}$, los resultados sirven más a los asesores de los políticos que a nosotros, los destinatarios de sus discursos. El motivo de tal situación es que las personas que se especializan en echar una mano a los políticos para que puedan influir y persuadir mejor a sus electores, aprenden y se sirven de los principios pragmalingüísticos que regulan el uso del lenguaje, mientras que la mayoría de nosotros, sus receptores, ni nos damos cuenta de su existencia.

En suma, aunque la imagen estereotipada de los políticos contemporáneos no sea muy atrayente, a veces no se sabe bien dónde termina la ignorancia y empieza la manipulación.

\section{Definiciones y análisis básicos}

En términos muy generales, para un lingüista el discurso es el uso que de la lengua hacen los hablantes en unas situaciones determinadas. La palabra "discurso" significa, pues, el uso de la lengua en las diversas actividades comunicativas. Si por "comunicación humana" entendemos el acto en el que dos o más personas comparten informaciones, opiniones, experiencias, sentimientos, etc., e interactúan entre sí, no es fácil imaginarse tal actuación sin el uso, por lo menos, mínimo de la lengua.

La comunicación verbal forma la parte básica de la comunicación humana. Cada acto comunicativo está sometido a unas reglas. Si, por ejemplo, se efectúa en forma de diálogo, los participantes suelen turnarse en los papeles de emisor y receptor. Es bien sabido que, especialmente en los debates de los políticos, este sistema platónico del diálogo es muy poco respetado. Otros factores por los que viene condicionado el éxito de la comunicación son:

${ }_{1}^{1}$ Se entiende por Pragmática o Pragmalingüística la disciplina cuyo objeto de estudio es el uso del lenguaje en función de la relación que se establece entre enunciado-contexto-interlocutores. Dicho de otro modo, la pragmática se interesa por analizar cómo los hablantes producen e interpretan enunciados en contexto; de ahí que tome en consideración los factores extralingüísticos que determinan el uso del lenguaje, a los que no puede hacer referencia un estudio puramente gramatical, tales como los interlocutores, la intención comunicativa, el contexto o el conocimiento del mundo. Diccionario de Términos Clave de ELE en línea: http://cvc.cervantes.es/ensenanza/biblioteca_ele/diccio_ele/diccionario/actodehabla.htm (05.08.11)

2 Political language $-/ \ldots /$ - is designed to make lies sound truthful and murder respectable, and to give an appearance of solidity to pure wind.

${ }^{3}$ Los lingüistas más célebres cuyas teorías han contribuido al desarrollo de la disciplina y han inspirado nuestro estudio son: Ducrot y Anscombre, (1983), Mainguenaneau (1976, 1991), van Dijk (2001), Kerbrat-Orecchioni (1991, 2001) y Martín Zorraquino y Portolés (1999). 
- el conocimiento del código en que están codificados los signos del mensaje;

- la orientación en los esquemas y modos de organizar el discurso en la comunidad lingüística;

- los conocimientos enciclopédicos y las experiencias comunicativas compartidas por los interlocutores.

El código en que están cifrados los signos del mensaje es, básicamente, el código verbal, pero en cada discurso están implicados también otros sistemas de signos como los acústicos o los visuales. Y todos ellos pueden influir en la recepción del mensaje. No menos importante es la orientación en los esquemas y modos de organizar el discurso en la comunidad lingüística en que éste se efectúa. Tanto el emisor como el receptor deben estar familiarizados con los llamados "esquemas" o "guiones" comunicativos según los cuales se organiza el discurso en una comunidad lingüística concreta. Sin estos conocimientos, no es posible planificar ni llevar correctamente el discurso.

Los esquemas comunicativos aparecen por primera vez en la obra de D. Hymes $(1974)^{4}$ sobre la etnografía de la conversación en la cual el estudioso analiza el uso de la lengua en culturas menos conocidas. En términos generales una de las condiciones necesarias para el éxito del discurso es que los interlocutores utilicen el mismo esquema comunicativo. Si, por ejemplo, el receptor no sabe qué esquema está utilizando el emisor, no es capaz de identificar la actividad en la cual está comprometido, ni captar la intención comunicativa. Los esquemas o marcos son culturalmente determinados y los creados en una cultura no siempre coinciden con los creados en otras.

El último elemento básico de un discurso de éxito son los "conocimientos enciclopédicos" y las "experiencias comunicativas" compartidos por los interlocutores. Ellos son indispensables para desarrollar unos procesos de inferencia que permiten al emisor comunicar y al receptor captar mensajes sin necesidad de hacer explícitas las ideas, por mera asociación con algún conocimiento enciclopédico o experiencia compartido anteriormente. Estos conocimientos y experiencias compartidos permiten también a los interlocutores emplear diversos recursos discursivos tales como la "ironía" o "implicaturas conversacionales". En definitiva, habida cuenta de la variabilidad de los factores que condicionan el éxito del discurso, el hecho de respetar los tres susodichos elementos disminuye -aunque no elimina- el riesgo de deficiencias y malentendidos en la comunicación.

El "análisis del discurso" es una disciplina científica que hoy día ha cobrado una especial importancia y está desarrollándose dinámicamente. Se efectúa en distintos ámbitos sociales y en diversos niveles. Uno de los fundadores del análisis crítico del discurso, Teun van Dijk dice:

${ }^{4}$ Aunque el concepto de marco o esquema fue acuñado por el antropólogo G. Bateson en 1955

5 Más sobre la determinación cultural de los espacios, marcos y guiones escribimos en WilkRacięska, 2010 y 2012: 18-64. 


\begin{abstract}
“Teóricamente se hace hincapié en que la disciplina < estudios del discurso $>$ debería tratar tanto de las propiedades del texto como las de la conversación, y de lo que se denomina el contexto, es decir, las otras características de la situación social o del suceso de la comunicación que puede influir sobre el texto o la conversación. En suma el análisis del discurso estudia la conversación y el texto en el contexto.” (Dijk, 2001: 24)
\end{abstract}

La definición básica del discurso, comúnmente aceptada por los lingüistas y, a la vez, la más conocida es la formulada también por Teun van Dijk, quien dice que, "simplemente, se puede describir el discurso como un hipertexto: una macroestructura formada por el texto y su contexto, es decir que podemos entenderlo como un sistema de signos codificados en el marco del contexto social de la creación, recepción y divulgación de este sistema." (Dijk, 2001: 11-13)

El discurso es, pues, una dimensión dinámica, un proceso de producción del texto en un contexto dado. Por este motivo tenemos que diferenciar rigurosamente entre el "discurso" (o "hipertexto") y el "texto" que, siendo un producto resultante del proceso, es estático.

Pasemos ahora a las nociones de "macroestructura" y "microestructura". La "macroestructura" será una estructura profunda, la disposición que forman entre sí todos los elementos del discurso, mientras que la "microestructura" es la coherencia entre enunciados. Cada una de ellas tiene sus reglas y unidad. Juntas aseguran la coherencia global del discurso. Dicho con otras palabras, la coherencia global del discurso depende de la competencia idiomática (texto) y la competencia comunicativa (visión del mundo, conocimientos enciclopédicos, experiencias, percepción de la realidad) del emisor y receptor ${ }^{6}$. El objetivo del análisis del discurso es descubrir y evaluar el verdadero comunicado que éste transmite y no la intención del emisor. Por ello, el análisis del discurso consiste en examinar toda su estructura, todos los elementos que lo forman. Por este motivo, en aquel análisis se toman en consideración tanto los elementos lingüísticos (tipos de palabras usadas, formas gramaticales, elementos fonéticos, etc.), como los diversos factores y tipos del ya mencionado contexto en que se realiza cada actuación lingüística. En estos factores encontramos, entre otras cosas, las normas socioculturales, sociolingüísticas y discursivas de la comunidad lingüística en la que el discurso se realiza.

\title{
3. Análisis pragmalingüístico de la argumentación: manipulación
}

Como cada acto comunicativo, el discurso también está sometido a muchas reglas, tanto lingüísticas como pragmáticas. En el caso del discurso político o periodístico, entre las reglas pragmáticas, las más importantes son las que regulan las maneras de argumentar. Es bien sabido que ya Aristóteles distinguía los textos argumentativos (científicos, dialécticos y retóricos) de los poéticos y de los históricos. Los estudios de la argumentación han sido refundados en la segunda mitad del siglo XX en la llamada "nueva retórica"? . No obstante, en la nueva retórica se considera que el lenguaje

6 Para más información sobre este punto de vista véanse Wilk- Racięska, 2007 y 2012.

7 A partir de los trabajos de Ch. Perelman y L. Olbrechts-Tyteca (1958), S. Toulmin (1958), y J. C. Anscombre y O. Ducrot (1983), fundamentalmente. 
sirve ante todo para persuadir, para convencer al interlocutor. Así pues, lo que define la naturaleza del lenguaje es su carácter persuasivo.

En la nueva retórica existen dos tipos de argumentación que difieren entre sí, ante todo, en el tipo de argumentos utilizados (verdaderos y verosímiles, respectivamente). Fue S. Toulmin (1958) quien en Los Usos de la Argumentación por primera vez se planteó esta separación dividiendo la lógica en dos tipos: la "formal" (que era lo que hasta entonces se entendía por "lógica aristotélica") y la "informal", de la cual se ha desarollado una de las teorías de la argumentación a la que volveremos más adelante.

Otra división, ya estrictamente lingüística, es la propuesta por Anscombre y Ducrot (1983). Según Anscombre y Ducrot el primer tipo es la "argumentación lógica", aristotélica, y el segundo, la "conversacional". En la argumentación lógica todas las premisas son verdaderas y bien documentadas. Por este motivo el discurso político y periodístico deberían fundamentarse tan solo en este tipo de argumentación. El esquema de tal argumentación es el siguiente: "argumento verdadero explícito > conclusión".

Sin embargo, es muy raro que los políticos se sirvan de argumentos lógicos; la mayoría de ellos suele basar sus discursos en la "argumentación conversacional" cuyos argumentos son verosímiles, estereotipados y no documentados. La pregunta que se plantea de inmediato es ¿cómo consiguen que tengamos confianza en sus palabras?

Recordemos que, según Aristóteles, el razonamiento argumentativo además de los argumentos explícitos utiliza "tópicos" ("topos"), conocimientos comunes almacenados en la memoria latente que se suponen admitidos por una comunidad sociolingüística y que establecen ciertos vínculos pragmáticos entre enunciados. Anscombre y Ducrot han estudiado especialmente el problema de los tópicos que funcionan como un tercer elemento -implícito- de la argumentación: "Argumento explícito + argumento implícito (tópico) > conclusión"

En la teoría de la argumentación, cada enunicado por su significado favorece unas conclusiones y dificulta otras, es decir, todo enunciado tiene una capacidad argumentativa. Por ello, los enunciados pueden ser analizados también como "argumentos" que apoyan una determinada conclusión. Por ejemplo, el enunciado (1) "este chico es un genio de la música", implica por su significado una conclusión del tipo (2) "sabe tocar muchos instrumentos", o bien (3) "comenzó a rondar los escenarios a los 3 años" y no, en cambio, la conclusión (4) "no consigue aprender a tocar el piano", que resultaría extraña. Por lo tanto, los enunciados (2) y (3) mantienen la "orientación argumentativa" del primero, pues son conclusiones inferibles del argumento que constituye el primer enunciado. En cambio, (4) "no consigue aprender a tocar el piano" es un enunciado "antiorientado" argumentativamente en relación a (1), pues no es una conclusión que se infiera de él. La relación argumento-conclusión está asegurada por el sentido de la palabra "genio" ("El genio es una persona que posee una inteligencia o aptitud extraordinaria").

Los sentidos de las expresiones lingüísticas son argumentos implícitos, pero verdaderos, pues son lógicos. No obstante, existen otros argumentos relacionados con los lógicos a través de distintas asociaciones (experiencia, mitos, etc.) que no son verdaderos pero sí, verosímiles y por tanto fácilmente aceptables. Por ejemplo, la relación argumento-conclusión (5) "este chico es un genio pues es insoportable" parece ver- 
dadera, porque la coherencia del argumento explícito ("este chico es un genio") y la conclusión ("es insoportable") se apoya en el "tópico" implícito siguiente: "los genios suelen ser insoportables", que de ninguna manera es una condición sine qua non para ser un genio.

Un "tópico" es, pues, un instrumento lingüístico muy poderoso que define la adecuación de los enunciados con respecto al contexto lingüístico en que aparecen, es decir, lo que es -o nos parece ser- adecuado como continuación a una determinada frase. Veamos un ejemplo de Mariano Rajoy:

"Con el objetivo de ahorrar costes a los ciudadanos y evitar duplicidades, hoy hemos aprobado la reforma de la administración local"

El primer ministro no explica en qué consiste esta reforma, pero sus palabras pueden satisfacer a los lectores porque se basan en el tópico implícito siguiente: "la reforma es un cambio de algo para su inovación y mejora" lo que implica: "la reforma siempre es buena".

Aunque, como sabemos, esta conclusión no siempre es verdadera, la relación argumeno-conclusión es verosímil, pues, aceptable. El razonamiento que se impone al lector será, entonces, el siguiente:

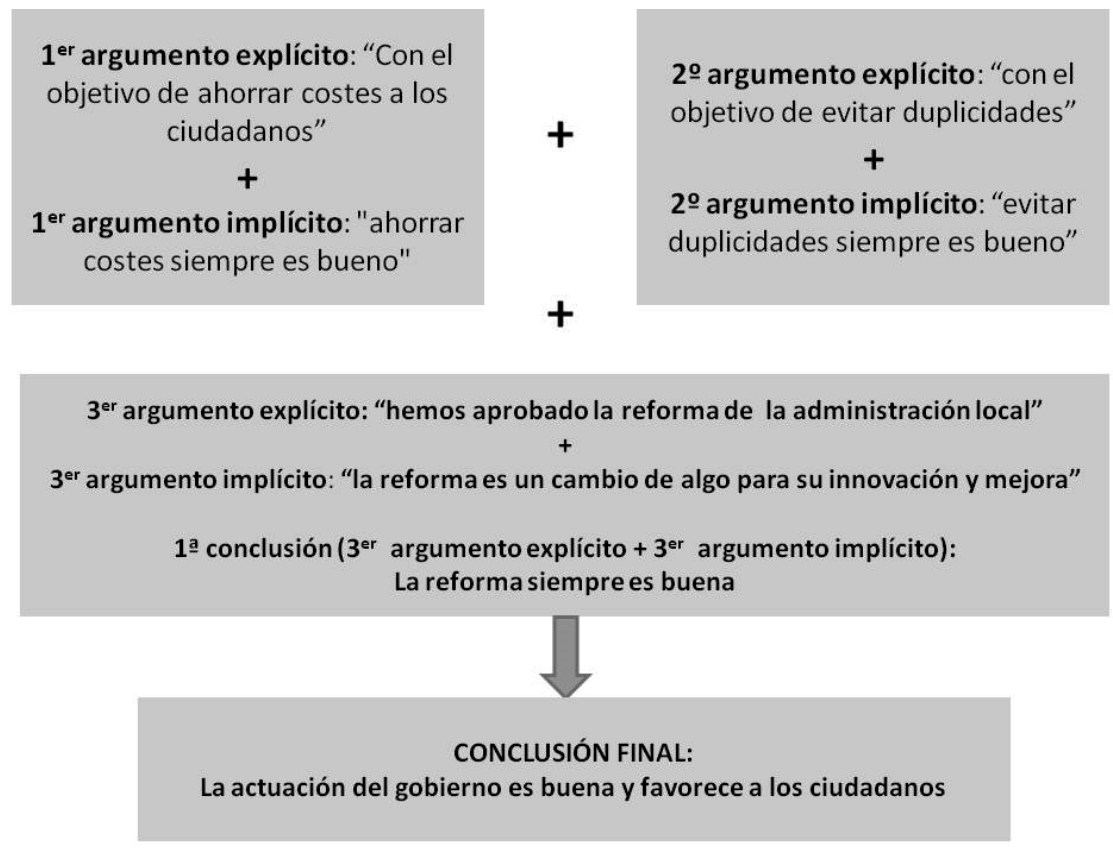

Otro marco de análisis para el estudio del significado que nos permite entender y explicar la aceptabilidad de los discursos apoyados en los argumentos conversacionales son los llamados "marcadores del discurso". M A. Martín Zorraquino y J. Por-

${ }^{8}$ https://pl-pl.facebook.com/pages/Mariano-Rajoy-Brey/54212446406 
tolés, (1999) afirman que en el significado de estas unidades lingüísticas encontramos las "instrucciones argumentativas" que nos permiten vincular los argumentos. Y así, para vincular dos argumentos "antiorientados" es preciso utilizar los llamados "marcadores/conectores contraargumentativos" que indican contradicción u oposición (p. ej.."en cambio"); para vincular dos argumentos "coorientados", se emplean, por ejemplo, "marcadores de refuerzo argumentativo" (p. ej.: "de hecho", "en realidad", etc.). Además de indicar una orientación determinada, los argumentos poseen también una "fuerza argumentativa". Martín Zorraquino y Portolés afirman que, si varios argumentos son "coorientados", podemos emplear algunos marcadores del discurso que indiquen cuál de ellos tiene más fuerza".

Veamos dos ejemplos de la manipulación de los marcadores discursivos en la argumentación conversacional durante el famoso debate Zapatero-Rajoy en marzo de 2008:

"Veo que usted no tiene el más mínimo interés en hablar de inmigración, pero yo sí y los españoles también, por tanto yo voy a hablar"10

Los argumentos explícitos junto a los implícitos (tópicos) llevan a la conclusión: "yo soy mejor político español que tú". Además, la instrucción argumentativa (implicación implícita) que dice "los argumentos vinculados por $<$ pero $>$ deben ser antiorientados" introduce una fuerte oposición entre tú y yo a la conclusión final:

" yo estoy con los españoles, (pues soy bueno)

» Tú estás contra los españoles, (pues eres malo)

En esta enunciación "pero" no solamente vincula dos argumentos que el enunciador considera antiorientados sino que sirve también para reforzar y destacar la diferencia entre los dos políticos. Este conector desempeña la misma función en el enunciado siguiente:

"Usted se atreve a hablar de nuestro modelo de España, de los consensos constitucionales. ¡Pero si el PSOE es el eje central de la democracia en España...!"”11

Las investigaciones de los estudiosos de la teoría de la argumentación permiten también descifrar los mecanismos de crear argumentos "conversacionales" o "informales" que ya no tienen mucho que ver con el discurso racional.

Existen cuatro reglas del discurso racional (según Hołówka, 2007: 18):

- la de la libertad de expresión;

- la de la responsabilidad por sus opiniones;

9 María Victoria Escandell Vidal lo explica del modo siguiente (Escandell, 1993:114): "María es muy lista: habla inglés, francés e incluso chino". El marcador "incluso" introduce el más fuerte de los argumentos empleados: puesto que en Europa existe el "tópico" de que el chino es una lengua muy difícil, saber chino es un argumento de más fuerza en la "escala argumentativa" que saber francés o inglés, de modo que le corresponde el lugar que viene introducido por "incluso".

${ }^{10} \mathrm{http}: / /$ elpais.com/elpais/2008/02/26/actualidad/1204017419_850215.html

${ }^{11} \mathrm{http}: / / w w w . e l i m p a r c i a l . e s: 6681 /$ hemeroteca/2008/03/04/contenido/5611.html 
- la de la honestidad con el interlocutor

- la de calidad ${ }^{12}$.

La libertad de expresión, que es uno de los derechos humanos fundamentales, sólo impone a los participantes en debates políticos dos restricciones: los interlocutores deben respetar los principios de cortesía y los turnos a la hora de presentar sus opiniones. Y aquí entran dos tipos de argumentos que no tienen nada que ver con la argumentación lógica ${ }^{13}$. El primero es el argumentum ad personam/ ad hominem, es decir el de criticar al adversario sus métodos, incompetencia o falta de programa. Por ejemplo, durante su intervención en un mitin celebrado en Valencia, Zapatero afirmó: "Cogen la gripe unos cuantos militares ${ }^{14}$, y piden la dimisión de la ministra de Defensa, /.../ ¿Cómo es posible tener tan poca seriedad, tan poca credibilidad?”.

Rajoy, por su parte, criticó que la ministra de Defensa "aún no haya dado explicaciones" y se haya dedicado a "ir hoy con las cámaras". Según dijo, "al PSOE no le importa el fondo del asunto, sólo las fotos y los anuncios"15.

Muy a menudo son los epítetos peyorativos los que entran aquí en juego y hasta el método de acallar a gritos al oponente:

"Usted mintió a los españoles cuando dejó que el Partido Comunista de las Tierras Vascas, ETA, se presentara a las elecciones. Usted mintió a los españoles cuando dejó que una parte de ANV se presentara a las elecciones. Usted mintió a los españoles cuando dejó que Juana Chaos se diera paseos por San Sebastián [...] Usted mintió a los españoles cuando calificó al señor Otegui como un hombre de paz [...] Usted mintió a los españoles cuando dijo que nunca hablaría de política con ETA"16.

La palabra "mentir" lleva una carga muy ofensiva si el enunciador no ofrece un buen argumento que defienda su acusación. Como vemos los argumentos alegados son típicamente conversacionales / informales, porque "mentir" es una acción lingüística que consiste en decir o manifestar lo contrario de lo que se sabe, cree o piensa en un momento dado, mientras que los argumentos alegados revelan las actitudes del oponente y no sus pensamientos o conocimientos y pueden testificar a lo más una deslealtad pero no mentiras. No obstante, la palabra "mentira" es mucho más fácil de entender y po ello suena mucho más fuerte.

Otro argumento, argumentum ad baculum, consiste -como sabemos- en amenazar al oponente con consecuencias por sus métodos o hechos usando las amenazas como si fueran razones. Lo ilustra muy bien el comentario que hizo el presidente interino de

${ }^{12}$ Aunque las infracciones de esta regla son numerosas, no la trataremos aquí, porque su explicación es más socio- o psicológica que lingüística.

${ }^{13}$ Esta rama de la teoría de la argumentación se ha desarrollado a partir de la idea de $\mathrm{S}$. Toulmin (1958), entre otras teorías

${ }^{14}$ Según El Mundo, la gripe A ha entrado en campaña electoral 2011 a raíz del brote de esta enfermedad en el acuartelamiento de Hoyo de Manzanares (Madrid): http://www.elmundo.es/elmundo/2009/05/23/espana/1243082730.html

${ }^{15} \mathrm{http}: / / w w w . e l m u n d o . e s /$ elmundo/2009/05/23/espana/1243082730.html

${ }^{16} \mathrm{http}: / / w w w . s o i t u . e s /$ soitu/2008/03/04/actualidad/1204588794_399564.html 
Venezuela, Nicolás Maduro durante un mítin de campaña en la Amazonia venezolana pronosticando que una maldición ancestral caerá sobre aquellos que no voten por él:

"Si alguien del pueblo vota contra Nicolás Maduro, está votando contra él mismo, le está cayendo la maldición de Maracapana"17

La segunda regla reza que los participantes del discurso político deben responsabilizarse de lo que dicen. Ello significa que todo participante de un debate debe ser capaz de aportar pruebas y documentar sus teorías y opiniones. Ya sabemos que son pocos los que siempre respetan esta regla. En la mayoría de los casos, los interlocutores se sirven de los conceptos no bien definidos, es decir, ambiguos o con bordes semánticos difusos que pueden servir para reforzar los reproches. Por ejemplo, a juicio del senador popular Antonio Ayllón:

"los dirigentes del PSOE en Granada son incapaces de trabajar con lealtad institucional con el Gobierno de España sobre el proceso de la reforma de la PAC, anteponiendo siempre sus intereses partidistas en lugar de trabajar en beneficio de la agricultura andaluza y granadina" 18 .

Las palabras del senador son demasiado fuertes, pero la definición del concepto de "lealtad institucional" 19 se compone de conceptos con bordes muy difusos y por consiguiente permite proteger a las personas que la usen de consecuencias jurídicas.

No obstante, mucho peor resulta el uso de las teorías y opiniones que no se pueden fundamentar. Por ejemplo, el ya mencionado Nicolás Maduro en uno de sus discursos consideró una "oferta engañosa" la de la oposición unida, que "a lo interno tienen una guerra de ambiciones, de imponer sus planes" ${ }^{20}$.

La cuestión aquí no es que la oferta sea o no engañosa, sino que no hay manera de verificarlo en el momento.

De acuerdo con la tercera regla, cada participante en el debate debe ser honesto con su oponente, es decir, comportarse y expresarse con sinceridad y de manera coherente, polemizando con las verdaderas opiniones del oponente y no con lo que él mismo se imagina. Vamos a explicarlo con el siguiente ejemplo. En 2007, la ALDF de México aprobó el dictamen por el que se despenaliza el aborto de la primera a la duodécima semana y se obliga al gobierno capitalino a "otorgar servicios de consejería médica y social gratuita en materia de atención a la salud sexual y reproductiva"/.../21.

En 2008 la cúpula sacerdotal de México critica:

${ }^{17} \mathrm{http}: / /$ www.proceso.com.mx/?p=338355

${ }^{18} \mathrm{http}: / /$ www.teinteresa.es/andalucia/granada/PP-confrontar-PSOE-Gobierno-PAC_0 964705167.html\#WaQ12kfGBWApjVAB)

${ }_{19}$ Definida en el Régimen Jurídico de las Administraciones Públicas y del Procedimiento Administrativo Común accesible en la página del gobierno

${ }^{20} \mathrm{http}$ ://www.telam.com.ar/vernota.php?tipo=N\&dis=1\&sec=1\&idPub=231870\&id=438532 \&idnota $=438532$ )

${ }^{21} \mathrm{http}: / /$ www.eluniversal.com.mx/notas/701962.html 
"Cuando políticas como el aborto y la eutanasia son dictadas desde el mismo seno de la ONU, para tratar de reducir la población mundial a fin de que los recursos se aprovechen mejor, en beneficio de unos cuantos gobiernos o empresas"22.

Como vemos, la cúpula sacerdotal de México no polemiza con el contenido de la ley sino con lo que a los sacerdotes les parece ser su objetivo.

Otro argumento, argumentum ad populum, consiste en aprovechar la animadversión de las clases populares a las élites económicas e intelectuales y es muy utilizado en los discursos de los políticos que quieren contar con los votos del pueblo llano. Se hizo popular justamente en el momento de la aparición de "las masas" más o menos concienciadas políticamente. Es un populismo en el sentido peyorativo, una estrategia de poder. Es aquí donde aparecen conceptos como "clientelismo", "caciquismo", "nepotismo", "lucha entre el pueblo y la oligarquía", "lucha entre nosotros y ellos". Veamos un ejemplo muy ilustrativo que no requiere explicaciones:

"el cambio de actitud del PSOE hacia el sectarismo y la radicalización únicamente perjudica a los agricultores andaluces" ${ }^{, 23}$.

\section{Los principios de la cohesión de la microestructura}

El análisis del elemento léxico forma la parte fundamental del análisis del discurso político. Los sentidos de las palabras no se han fijado de una vez por todas y cuando se emprende el análisis del discurso político, hay que tener en cuenta la relación de imbricación entre la palabra y su contexto, tanto lingüístico como extralingüístico. Toda la argumentación se realiza con palabras vinculadas entre sí de distintos modos, mediante distintos tipos de enlaces y conectores, los cuales, dicho sea de paso, aportan por sí mismos- importantes significados discursivos.

Por lo tanto, cualquier análisis del "hipertexto" ("discurso") debe empezarse por el análisis de su "microestructura": el léxico, la gramática y todos los elementos que aseguran la coherencia intratextual (“cohesión”), la cual garantiza la unión del texto, la conexión de todas sus partes en un todo. Los instrumentos que permiten asegurar la cohesión son, entre otros, la recurrencia, la repetición, las anáforas, la elipsis, los conectores intratextuales, etc. No obstante, el empleo de todas aquellas herramientas es regulado por una serie de principios de la cohesión de la microestructura:

- el de la progresión de información,

- el de la combinatoria léxica,

- el de la continuidad ${ }^{24}$

- el de la no-contradicción lógica (según Reichler de Béguelin, 1988).

${ }^{22}$ Idem.

${ }^{23} \mathrm{http}$ //www.europapress.es/andalucia/noticia-pp-reprocha-falta-lealtad-obsesion-confrontarpsoe-gobierno-relacion-pac-20130729200236.html

${ }^{24}$ Según este principio, el discurso no puede aportar las informaciones exclusivamente nuevas. Para garantizar la continuidad, es indispensable que la información novedosa tenga un soporte en la información ya presentada. La infracción de esta regla no es muy frecuente, porque nos comunicamos siempre en un contexto sociolingüístico o situacional que sirve de anclaje para las informaciones nuevas. No obstante, una variación de la infracción del principio de la continuación la encontramos, a veces, en las respuestas de los políticos cuando se les pregunta por sus programas. 
No es posible asegurar la coherencia global del discurso sin respetar estos cuatro principios.

Según el principio "de la progresión de información", un enunciado debe aportar, por lo menos, una información nueva respecto a la oración precedente. Ello significa, simplemente, que hablamos para comunicarle a nuestro interlocutor una información que creemos que él todavía no conoce. Así, por ejemplo, de la respuesta a la pregunta:

- "¿Dónde está mi bolsa?

- Tu bolsa está en el armario"

el emisor ha aprendido algo. Pero el siguiente fragmento de la enunciación de Aznar ya no parece aportar nada nuevo al discurso:

"Puede haber razones, puede haber problemas de otro tipo de razones en el espacio aéreo y, en fin, puede haber otros problemas" ${ }^{\prime 25}$.

El fragmento citado es un ejemplo típico de la tautología, que a la vez es una de las infracciones del principio "de la progresión de información" más típicas. Las tautologías puras sólo se permiten en lógica y matemáticas, pero a veces se emplean, también, para explicar el sentido de los términos más complejos, con palabras menos complejas semánticamente como por ejemplo: "El soltero es un hombre no casado"

Por otra parte, las tautologías pueden emplearse también en poesía, literatura o lenguaje corriente como enunciados pragmáticamente cargados de sentido. Este uso de tautologías podríamos llamarlo "tautologías aparentes desde un punto de vista discursivo", puesto que su empleo aporta más información de lo que parece a primera vista. El conocimiento enciclopédico, la experiencia, en definitiva, el contexto extralingüístico compartido tanto por el enunciador como por el receptor, le permite al segundo descifrar el mensaje que vehicula una tautología aparente. Por ejemplo, los que tienen hijos, entienden perfectamente el mensaje del enunciado: "un hijo es un hijo", los que tienen jefes dicen "un jefe es un jefe" y todos nosotros repetimos a veces "la vida es la vida". En suma, siendo una tautología desde el punto de vista lógico, tal enunciado no lo es desde el punto de vista pragmático. Por este motivo, al contrario de lo que puede parecer a primera vista, las tautologías aparentes se utilizan mucho en el lenguaje corriente.

Citemos un ejemplo de tautología justificada presentado por Felipe Calderón, el ex presidente de México, durante el evento "Diálogos por la seguridad. Hacia una política de Estado"(14.05.2007):

"Debemos recordar que son, precisamente, quienes cometen los crímenes, los criminales; que quienes realizan la violencia son los violentos; que quienes hacen los homicidios, quienes los cometen, son los asesinos, no la autoridad, que está obligada a someter a esos criminales, y a enfrentar a esos asesinos" ${ }^{\prime 26}$.

${ }^{25} \mathrm{http}$ //infotk.blogs.com/infotk/2003/10/frases_y_ocurre.html

${ }^{26} \mathrm{http}: / /$ www.tintajarocha.com/rp_not.php?id= $\overline{24632}$ 
Aunque el uso de este recurso parezca extraño, el presidente utilizó la tautología aparente para subrayar la distinción entre dos grupos de personas. Por lo general, las infracciones aparentes de la regla de progresión de la información pueden ser un recurso lingüístico muy útil. No obstante, existen infracciones que no se pueden explicar ni mediante la gramática, ni la pragmática. Veamos un ejemplo de J. M. Aznar:

"Augusto Pinochet me parece un personaje que pertenece a la historia de Chile y a su modelo de transición política"27.

Veamos también un típico argumento ad personam donde no hay mucha progresión de información:

"El principal obstáculo ha sido una oposición que no aceptó el resultado electoral. Que ha crispado, que ha enfrentado a unos ciudadanos de unas comunidades con otras, que se ha movido entre la mentira y la exageración, que no ha dudado en utilizar el terrorismo con fines partidistas, que no ha dudado en utilizar el dolor de las víctimas. Una oposición que ha establecido la división y la crispación" 28 .

En resumen: se le informa al público de que la oposición ha crispado y, en consecuencia, ha establecido la crispación.

Así las cosas, podemos resumir que el principio de la progresión de información es una regla muy importante que tenemos que respetar, si queremos dar a nuestros interlocutores una información concienzuda y honesta. No obstante, como hemos observado hasta ahora, los políticos y otros personajes famosos, no siempre la respetan. Quizás ¿porque no tienen mucho que decir?

Con el principio de la progresión están íntimamente ligados el principio de la combinatoria léxica y el de la continuidad.

El principio de la combinatoria léxica establece que los significados de los términos en el discurso deben combinarse entre sí de acuerdo con la combinatoria semántico-sintáctica, que es una de las reglas lingüísticas básicas de nuestro sistema macro ${ }^{29}$, es decir, que resulta de nuestra experiencia y conocimiento del mundo. Con otras palabras, se podría decir que una persona que viola el principio de la combinatoria léxica no cumple con las reglas de la visión del mundo comúnmente aceptadas. Para ilustrar lo dicho imaginémonos qué haríamos si uno de nuestros amigos nos dijera con toda seriedad: "Mi perro lee todos los periódicos antes que yo" Visto que, según nuestro conocimiento del mundo y la experiencia, los perros no saben leer, el sentido del predicado y el del sujeto de este enunciado han sido "mal combinados". Si esta combinación disparatada se ha hecho de forma intencionada, todo está bien. ${ }^{30}$ Sin embargo, no siempre es así. La in-

${ }^{27} \mathrm{http}: / /$ infotk.blogs.com/infotk/2003/10/frases_y_ocurre.html

${ }^{28} \mathrm{http}: / /$ elpais.com/elpais/2008/02/26/actualidad/1204017419_850215.html (El País, 26.02.08.)

${ }^{29}$ La distinción entre sistemas macro y sistemas de menor entidad la explico, entre otros trabajos, en J.Wilk-Racieska 2007

${ }^{30}$ Añadimos que en esta infracción se fundamentan, entre otros, los argumentos conversacionales llamados argumentos post hoc, ergo propter hoc: que representan una conexión causal entre dos hechos solo porque uno ocurra antes del otro: "Vino Paco y ganamos el premio, por tanto, su llegada causó nuestro éxito". 
fracción más típica de esta regla se comete cuando no nos fijamos bien en el sentido de las palabras empleadas, o bien, simplemente confundimos su sentido. Hace unos años el entonces presidente venezolano Hugo Chávez sostenía:

"Bueno, en fin: la pobreza, los campos arrasados, la desnutrición, las enfermedades, casi todo está privatizado" ${ }^{\prime 1}$

Habida cuenta de que se privatiza lo público podemos suponer que el mandatario venezolano trató las antedichas desgracias como bienes nacionales. El hecho de que el presidente Chávez, a pesar de lo que aparenta, no parecía desearle éxito a su pueblo se ve mejor años más tarde cuando, en uno de sus discursos, propone a su pueblo "la revolución perpetua".

Si nos fijamos en el sentido del término "revolución", veremos que su significado básico es el de "cambio violento en las instituciones políticas, económicas y sociales de un país", o bien, en su acepción más amplia "cambio rápido y profundo". En ambos casos, sin embargo, lo que implica la palabra "revolución" es un suceso rápido y brusco. Al contrario, el término "perpetuo" describe un proceso o estado que dura o que permanece para siempre. Así las cosas, reunir los dos términos de la manera que lo hace Hugo Chávez introduce una enorme confusión de perspectiva.

Es justamente la falta de atención a los matices semánticos, por un lado y la sensibilización de las emociones por el otro, lo que más se aprovecha en los discursos políticos. Los políticos suelen crear su propio lenguaje que se ajusta perfectamente a sus objetivos. Otro recurso utilizado en este procedimiento es el pleonasmo. Lo utilizamos, a veces, para su exacta y completa comprensión del término, pero, en la mayoría de los casos, creamos los pleonasmos por ignorancia. Una parte de los pleonasmos utilizados por los políticos tienen origen en su ignorancia. No obstante, los pleonasmos creados de una manera competente son una herramienta muy poderosa de persuasión porque aportan gracia y -ante todo- fuerza expresivas. Un ejemplo típico de pleonasmo con fuerza expresiva es el empleado por el presidente venezolano Nicolás Maduro:

"Tenemos que vencer las falsas ilusiones electoreras"32

La expresión "falsas ilusiones" es un pleonasmo ya que las ilusiones son falsas por definición, pero ¡qué fuerza persuasiva aporta el pleonasmo a la enunciación!

El discurso político es un acto de habla ${ }^{33}$ cuyo objetivo principal es persuadir. Al emitir un enunciado como, por ejemplo, "te prometo que lo haré" estamos, por un lado, diciendo algo (acto locutivo); prometiendo una acción (acto ilocutivo) y provo-

${ }^{31} \mathrm{http} / /$ www.taringa.net/posts/humor/2028474/Frases-Celebres-de-Famosos.html

$32 \mathrm{http}$ //www.eluniversal.com/nacional-y-politica/130728/maduro-llama-a-su-militancia-a-nodejarse-llevar-por-el-electoralismo (El Universal, 28.07.2013)

33 "El término "actos de habla" fue acuñado por un filósofo británico J.L. Austin. Según Austin, al producir un acto de habla, se activan simultáneamente tres dimensiones: Un acto locutivo (el acto físico de emitir el enunciado como decir, pronunciar, etc.)./.../; un acto ilocutivo o intención (la realización de una función comunicativa, como afirmar, prometer, etc.); un acto perlocutivo o efecto (la (re)acción que provoca dicha emisión en el interlocutor, como convencer, interesar, calmar, etc.) (Diccionario de Términos Clave de ELE, web) 
cando un efecto (convencer de la promesa al interlocutor). Para lograr este fin los políticos, además de los pleonasmos, utilizan otras herramientas lingüísticas. Nadie como ellos sabe formar las construcciones donde las palabras se unen de un modo inesperado y a veces chocante. Aunque tales construcciones, al igual que los pleonasmos, pueden surgir de la ignorancia o ser intencionadas. Si son intencionadas, sirven para crear un nuevo valor, un valor, que se presenta como algo fresco, enigmático y ante todo inteligente. Es bien sabido que lo que no entendemos implica algo enigmático, lo enigmático implica lo inteligente. Así que, aunque no es fácil de captar ni por lo menos de comprender el sentido de algunas extrañas construcciones, si a un receptor se le ocurre no entender alguna de ellas, no suele buscarle abiertamente el sentido para no parecer el menos inteligente. Aludimos otra vez a Hugo Chávez:

"No es lo mismo hablar de revolución democrática que de democracia revolucionaria. El primer concepto tiene un freno conservador; el segundo es liberador" ${ }^{34}$.

Todos sabemos, que la expresión "revolución democrática", es una elipsis semántica del tipo télico, que significa "una revolución que lleva a la democracia", es decir, un proceso violento cuyo resultado ha de ser el sistema de gobierno en que el pueblo ejerce la soberanía mediante la elección libre de sus dirigentes. No obstante, la "democracia revolucionaria" es una construcción semánticamente contradictoria, porque significaría una "democracia que se manifiesta a través de la revolución", siendo tal explicación un sinsentido, ya que el proceso revolucionario, por si mismo excluye la democracia.

Otros ejemplos del mismo autor son: el ya citado "revolución perpetua", que se puede interpretar tan solo como "cambio violento y profundo que nunca terminará" $\mathrm{y}$, de esta manera infringe dos principios, o bien el de "líderes orgánicos" donde "orgánico", de acuerdo con las reglas lingüísticas es un adjetivo calificativo y no relacional, es decir, caracteriza a los dirigentes como personas y no a su manera de dirigir.

Uno de los especialistas en crear construcciones que suenan muy eruditas pero, o bien no tienen sentido, o bien resultan contradictorias, es el jefe de la oposición polaca, Ley y Justicia, J.Kaczynski. Él mismo y los miembros de su formación están dotados de un don especial para inventar nuevos sentidos (peyorativos, en la mayoría de los casos), al unir los términos lingüísticos de manera chocante, o bien, darles sentido inesperado al incluirlos en contextos no apropiados. Citemos los ejemplos más conocidos de los neologismos del líder de la oposición polaca:

"lumpenliberalismo" -una variación de la palabra "lumpenproletariado"- sobre los partidarios del partido gobernante y oponentes de Ley y Justicia como personas marginadas y rechazadas por todas las capas sociales" ${ }^{\text {35 }}$

El objetivo de la creación de todas aquellas construcciones es influir en las emociones del pueblo. Su contenido incomprensible es como un arma nueva: tan rápido y chocante que no deja tiempo para pensar.

${ }^{34} \mathrm{http}: / / w w w . c a d e n a g r a m o n t e . c u /$ index.php/articulos/ver/16158:canciller-de-venezuela-califica-de-enganosa-oferta-de-la-oposicion(Caden@gramonte,01.10.11)

${ }^{35} \mathrm{http}$ ://www.fakt.pl/Oto-minislownik-Jaroslawa-Kaczynskiego-,artykuly,82081,1.html 
Siguiendo el tema de la combinatoria léxica no nos podemos olvidar de otro procedimiento muy característico: la perfilación de los sentidos en el contexto. Analicemos el siguiente ejemplo del expresidente venezolano Hugo Chávez:

"esa burguesía no va a sostener los planes sociales si alcanza el Ejecutivo"36

En algunos usos la palabra "burguesía" cobra un sentido de epíteto peyorativo, bien visible aquí gracias a dos recursos discursivos con los cuales el mandatario venezolano manipula a sus receptores. El primero de ellos es el contexto extralingüístico en que se ubica el discurso del presidente, quien está hablando a su pueblo: la gente pobre, sin trabajo, dinero, ni perspectivas. El segundo recurso, lingüístico, es el hecho de subrayar el valor negativo de "burguesía" con el empleo del demostrativo ese que en su uso secundario, es decir, cuando no indica distancia, adquiere un valor peyorativo. Estos dos recursos se utilizan en la argumentación argumentum ad populum que -recordemos- consiste en aprovechar la animadversión de la gente simple a los bien acomodados, mejor educados, etc. Y así nace el lenguaje del odio, que algunos políticos crean y manejan perfectamente.

Pasemos ahora, al "principio de la no-contradicción lógica". Esta regla parece ser una de las más odiadas por los políticos ya que es contra ella contra la que se cometen la mayoría de las infracciones. Este principio nos dice que si una de las oraciones precedentes afirma una cosa, las oraciones siguientes no pueden contradecirla explícita ni implícitamente. La contradicción explícita casi nunca sucede, pero a veces podemos encontrarla. Un ejemplo típico de la infracción del principio de la no-contradicción es una de las frases del famoso Homero Simpson: "Hijo, si de verdad quieres algo en esta vida, tienes que trabajar por ello. ¡Ahora cállate! Están por anunciar los números de la lotería" ${ }^{37}$, donde Homero contradice sus propias palabras. La verdad es que a todos nosotros nos ocurren contradicciones parecidas y no pasa nada. Otra cosa es, si son los políticos los que se contradicen en público.

Durante un debate político (13.10.2007), el entonces primer ministro polaco, J.Kaczyński rebatió las palabras acusadoras dirigidas hacia él por parte de otro político polaco, D. Tusk, de la siguiente manera:

"Nunca ocurrió nada parecido. D. Tusk tiene problemas evidentes de memoria, son, podría decirse, graves problemas de memoria. Un día ocurrió tal hecho, pero totalmente diferente y claro yo no dije <matarle es como escupir $>$ "'38.

Por otra parte, no podemos olvidar que el discurso político es un discurso instrumental cuya herramienta más importante debería ser una argumentación lógica y no la conversacional, bien equilibrada, basada en la validez y la eficacia de lo que se enuncia, así que las reglas fundamentales de la cohesión que acabamos de enumerar cobran aquí una especial importancia. En un discurso político hay que hacer hincapié sobre el hecho de que la regla de la no-contradicción no se limita a la no-contradic-

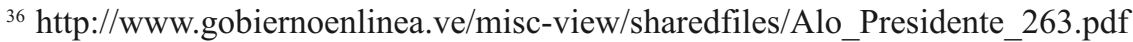

$37 \mathrm{http}: / /$ www.taringa.net/posts/humor/2028474/Frases-Celebres-de-Famosos.html

${ }^{38} \mathrm{http}$ ://www.pis.org.pl/article.php?id=10258 (13.10.2007)
} 
ción semántico-pragmática de no usar palabras y enunciados con sentidos contradictorios, sino que debe guardarse la no-contradicción entre los datos, las bases y el respaldo. Por este motivo, los argumentos no pueden depender de algún acuerdo o consenso ocasional. Se deben aceptar por ser irrefutables, no sólo porque responden al modelo lógico de inferencias sino por la confiabilidad y significancia de los resultados obtenidos mediante la probabilidad o la estadística; o sea, un simple conocimiento del mundo real. He aquí un ejemplo de la infracción de este principio que aparenta una deducción lógica:

"sólo hay un culpable que es Zapatero. ETA, ya sabemos que hace lo que lleva haciendo ya cuarenta años"39

\section{Conclusión}

El análisis de diversos aspectos -sociológico, psicológico, lingüístico- del discurso público ha demostrado ya muchas veces que este tipo de discurso tiene una importancia fundamental en la reproducción de las ideologías; por un lado, sirve para reforzar la identidad nacional, pero, por el otro, contribuye de manera fundamental a propagar, fomentar y difundir los estereotipos y prejuicios de carácter racial, étnico o nacional. No obstante, los análisis del discurso público separados según la disciplina son como las conclusiones de los ciegos de la leyenda hindú sobre los tres ciegos y el elefante: cada uno de ellos es valioso, pero permite conocer del elefante solamente por la parte que se ha tocado. Pero no al elefante. Por este motivo, para que nuestro "elefante" se deje conocer en su totalidad es necesario emprender investigaciones holísticas. En nuestro artículo hemos esbozado una aportación lingüística a tal estudio.

\section{Referencias bibliográficas}

ANSCOMBRE, Jean-Claude y DUCROT, Oswald (1983): La argumentación en la lengua. Madrid, Gredos.

BATESON, Gregory (1955): "A theory of play and fantasy. Steps to an ecology of mind", en: Psychiatric research reports. New York, Ballantine, pp. 177-193.

DIJK, Teun, A. van (2001): "Badania nad dyskursem", en DIJK, Teun A. van: Dyskurs jako struktura i proces, Warszawa, przeł, G. Grochowski.

ESCANDELL VIDAL, María Victoria (1993): Introducción a la pragmática. Anthropos-UNED, Barcelona.

HOŁÓWKA, Teresa (2007): Kultura logiczna w przyktadach. Warszawa, PWN

HYMES, Dell (1974): Foundations in Sociolinguistics: An Ethnographic Approach, Philadelphia, University of Pennsylvania Press

KERBRAT-ORECCHIONI, Catherine (2001): Les actes de langage dans le discours: théorie et fonctionnement. Paris, Nathan

${ }^{39} \mathrm{http}: / /$ www.youtube.com/watch?v=VxjrScc7EjY 
KERBRAT-ORECCHIONI, Catherine (1991-1992): Les interactions verbales. Paris, Armand Colin, tome 1.

MAINGUENANEAU, Dominique (1976): Initiation aux méthodes de l'analyse du discourse, Paris, Hachette.

MAINGUENEAU, Dominique (1991): L'analyse du discours. Introduction aux lectures de l' archive. Paris, Hachette.

MARTÍN ZORRAQUINO, Ma Antonia y PORTOLÉS, José (1999): "Los marcadores del discurso", en BOSQUE, Ignacio y DEMONTE, Violetta: Gramática descriptiva de la lengua española. Madrid, Espasa-Calpe, pp. 4051-4213.

ORWELL, George (1946): "Politics and the English Language", accessible en: http://www.resort.com/ prime8/Orwell/patee.html

PERELMAN, Chaïm y OLBRECHTS-TYTECA, Lucie (1989): Tratado de la argumentación. La nueva retórica. Madrid: Gredos, $5^{\text {a }}$ edición [Primera edición original: 1958].

REICHLER DE BEGUELIN, Marie-José (1988): Écrire en français. Paris, Neuchâtel

TOULMIN, Stephen (1958): The uses of Argument. Cambridge, C.U.P.

WILK-RACIĘSKA, Joanna (2007): "Nuestro mundo, nuestras visiones del mundo y las lenguas que lo describen todo...", en: Anuario de Estudios Filológicos, Extremadura, XXX/ Universidad de Extremadura, pp. 439-453.

WILK-RACIĘSKA, Joanna (2010): “¿Fuera de la norma? Las integraciones conceptuales y su utilidad en la descripción de las lenguas naturales"; en: WALUCH DE LA TORRE, Ewelina: La norma lingüistica del español. Encuentros 2010, vol I, Warszawa Wyd. MRL, pp. 33-40

WILK-RACIĘSKA, Joanna (2012): Entre la visión del mundo temporal y la aspectual. Casos del español sudamericano. Katowice, Wydawnictwo Uniwersytetu Śląskiego, 2012. 